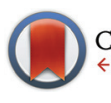

CrossMark $\leftarrow$ click for updates

Cite this: Dalton Trans., 2016, 45 5765

Received 21st December 2015, Accepted 24th February 2016

DOI: $10.1039 / c 5 d t 04961 j$

www.rsc.org/dalton

\title{
Sol-gel preparation of low oxygen content, high surface area silicon nitride and imidonitride materials $\uparrow$
}

\author{
Kripasindhu Sardar, ${ }^{a}$ Richard Bounds, ${ }^{a}$ Marina Carravetta, ${ }^{a}$ Geoffrey Cutts, ${ }^{b}$ \\ Justin S. J. Hargreaves, ${ }^{c}$ Andrew L. Hector, ${ }^{\star a}$ Joseph A. Hriljac, ${ }^{\text {b }}$ William Levason ${ }^{a}$ \\ and Felix Wilson ${ }^{a}$
}

Reactions of $\mathrm{Si}(\mathrm{NHMe})_{4}$ with ammonia are effectively catalysed by small ammonium triflate concentrations, and can be used to produce free-standing silicon imide gels. Firing at various temperatures produces amorphous or partially crystallised silicon imidonitride/nitride samples with high surface areas and low oxygen contents. The crystalline phase is entirely $\alpha-\mathrm{Si}_{3} \mathrm{~N}_{4}$ and structural similarities are observed between the amorphous and crystallised materials.

\section{Introduction}

Silicon nitride is promising as a heterogeneous catalyst support due to the high thermal conductivity and good oxidation resistance of $\alpha-\mathrm{Si}_{3} \mathrm{~N}_{4},{ }^{1,2}$ that make it a useful alternative to the more commonly used silica supports in reactions where effective heat transfer is required. Sol-gel derived amorphous silicon nitride is also interesting for solid base catalysis due to the presence of residual $\mathrm{NH}_{2}$ and $\mathrm{NH}$ groups, ${ }^{3,4}$ e.g. the Knoevenegal condensation of benzaldehyde and malonitrile to 1,1-dicyanophenylethylene. ${ }^{5}$ Due to these surface groups such materials are better referred to as imidonitrides. Bradley and co-workers developed the synthesis of the cyclic [Si( $\mu-\mathrm{NH})$ $\left.\left(\mathrm{NMe}_{2}\right)_{2}\right]_{3}$ and its ammonia-driven gelation, and heated the resultant gels under ammonia to produce high surface area imidonitrides. ${ }^{6}$ Incorporation of long chain amines into the gels enabled some pore size control in these catalysts, which possess high activity and selectivity in the alkylation of styrene with ethene, the alkylation of benzene with styrene and alkene isomerization reactions. ${ }^{7}$

Reactions of silicon alkylamides with ammonia parallel hydrolytic sol-gel processes to produce silica, with nucleophilic ammonolysis and condensation reactions

${ }^{a}$ Chemistry, University of Southampton, Southampton SO17 1BJ, UK. E-mail: a.l.hector@soton.ac.uk

${ }^{b}$ School of Chemistry, University of Birmingham, Birmingham B15 2TT, UK

${ }^{c}$ School of Chemistry, University of Glasgow, Glasgow G12 8QQ, UK

$\dagger$ Electronic supplementary information (ESI) available: Further electron micrographs, full structure refinement details (Rietveld and PDF), pair distribution functions to $r=90 \AA$, and raw diffraction data files. See DOI: 10.1039/c5dt04961j producing bridging imide groups ( $\mathrm{R}$ represents an alkyl group or $\mathrm{H})$ :

$$
\begin{gathered}
\mathrm{Si}\left(\mathrm{NR}_{2}\right)_{4}+\mathrm{NH}_{3} \stackrel{\text { Ammonolysis }}{\longrightarrow} \mathrm{Si}\left(\mathrm{NH}_{2}\right)\left(\mathrm{NR}_{2}\right)_{3}+\mathrm{HNR}_{2} \\
\mathrm{Si}\left(\mathrm{NH}_{2}\right)\left(\mathrm{NR}_{2}\right)_{3}+\mathrm{Si}\left(\mathrm{NR}_{2}\right)_{4} \stackrel{\text { Condensation }}{\longrightarrow}\left(\mathrm{NR}_{2}\right)_{3} \mathrm{Si}(\mu-\mathrm{NH}) \mathrm{Si}\left(\mathrm{NR}_{2}\right)_{3}
\end{gathered}
$$

Repetition of these processes leads to polymeric species of the form $\left[\mathrm{Si}(\mu-\mathrm{NH})_{x}\left(\mathrm{NH}_{2}\right)_{y}\left(\mathrm{NR}_{2}\right)_{z}\right]_{n}$ that have been processed to make high surface area powders, ${ }^{6,8}$ films, ${ }^{9}$ membranes $^{10}$ and monolithic aerogels. ${ }^{11,12}$ Jansen balanced ammonolysis rates between $\mathrm{Si}(\mathrm{NHMe})_{4}$ and metal amides to produce gels with metal ions dispersed through them, and fired these to produce amorphous $\operatorname{MSiN}_{x}$ materials and composites containing metal nitride nanoparticles. ${ }^{13}$ Sol-gel processing from $\left[\mathrm{Si}(\mu-\mathrm{NH})\left(\mathrm{NMe}_{2}\right)_{2}\right]_{3}$ has used trifluoromethanesulfonic (triflic) acid as a gelation catalyst and Cheng et al. suggested that the triflate rather than the protons was responsible for the increase in the ammonolysis and condensation rates, operating by displacement of $\mathrm{NMe}_{2}$ groups prior to nucleophilic attack on the silicon by ammonia. ${ }^{14}$

Our work on silicon nitride sol-gel processing has used $\mathrm{Si}(\mathrm{NHMe})_{4}$ with ammonia as previously described by Jansen, but introduced the triflic acid catalyst to control reaction rates as described by Bradley. ${ }^{9,11,15}$ This is an effective route to monolithic aerogels and coatings, and combines useful features from both previous approaches as the precursor system is straightforward but control over the gelation process is effective. However it requires very careful experimental control and a degree of extra skill as the triflic acid needs to be added accurately to the highly moisture sensitive solution at $-20{ }^{\circ} \mathrm{C}$ as the sol warms from $-78{ }^{\circ} \mathrm{C}$ after ammonia addition. We 
have also not previously examined the structural chemistry of these materials either in the amorphous state or during annealing. Our current interest in sol-gel derived silicon nitride and imidonitride stems from the possibility of using these high surface area materials for catalyst supports, and the incorporation of catalytically-active metal centres. ${ }^{4,16}$ Here we investigate the replacement of the triflic acid catalyst with ammonium triflate, which offers safer handling, lower risk of moisture contamination and better control over its addition. Gelation can be achieved with very low concentrations of this catalyst and hence the resulting materials have low oxygen contents, in contrast to materials previously reported from triflic acid-catalysed reactions. The resulting silicon imidonitride and silicon nitride materials are characterised in detail after firing at a range of temperatures. Future reports will examine metal incorporation into these materials and catalytic activities.

\section{Results and discussion}

\section{$\left[\mathrm{NH}_{4}\right][\mathrm{OTf}]$-catalysed gelation}

Preparation of silicon nitride precursor gels from $[\mathrm{Si}(\mu-\mathrm{NH})-$ $\left.\left(\mathrm{NMe}_{2}\right)_{2}\right]_{3}$ has typically used a triflic acid catalyst with a $\mathrm{TfO}^{-}$: Si ratio of $1: 100$ (1\% triflate) ${ }^{6}$ but up to $10 \%$ triflate (again relative to $\mathrm{Si}$, here and in all further references) has also been used in formation of gels containing dopants such as aluminum. ${ }^{10}$ Triflic acid is an aggressive reagent and is difficult to measure in small quantities. It is also a potential source of contamination both from the components of the triflate group itself and from moisture or from metal ions introduced through contact (e.g. with a syringe needle). Hence in our previous work based on $\mathrm{Si}(\mathrm{NHMe})_{4}$ we have rapidly added 1-2 drops (10 mg, 2-3\%) triflic acid from a glass pipette rather than attempting to measure it accurately., ${ }^{9,11} \mathrm{~A}$ further difficulty in the use of triflic acid is that the success of the reaction is dependent on the addition of the triflic acid in a narrow temperature window around $-20{ }^{\circ} \mathrm{C}$ as the $\mathrm{Si}(\mathrm{NHMe})_{4} /$ ammonia solution warms from $-78{ }^{\circ} \mathrm{C}$ and precipitation occurs if added outside this window. The addition of triflic acid to an ammonia-rich solution will clearly lead to the formation of ammonium triflate, which is a non-corrosive solid. To emulate the gelation times of the triflic acid-catalysed sols it was found to be necessary to add $5-10 \%\left[\mathrm{NH}_{4}\right][\mathrm{OTf}]$, although importantly this could be added to the $\mathrm{Si}(\mathrm{NHMe})_{4}$ solution before condensation of the ammonia. This simplification of the procedure means that it would be possible to scale up these reactions, a significant consideration for catalytic applications. The catalyst was introduced from a rigorously dry standard solution in THF, with the volume made up to a chosen level using further THF. Initially similar reagent concentrations to our previous studies were used, but TEM images (ESI, Fig. S1 $\dagger$ ) showed the resultant samples to contain large quantities of large $(\sim 500 \mathrm{~nm})$, spherical particles. The quantity of these larger particles was reduced by increasing the solvent volume to the level described in the Experimental section for all subsequent samples.

${ }^{29} \mathrm{Si}$ MAS-NMR is a sensitive probe for detection of oxygen contamination in silicon nitride, as these sites are associated with very different chemical shift ranges. ${ }^{16,17}$ Silicon near amide sites and $\mathrm{SiN}_{4}$ tetrahedra appear around -43 and $-49 \mathrm{ppm}$, respectively. If oxygen atoms occupy the $\mathrm{N}$ sites in $\mathrm{Si}_{3} \mathrm{~N}_{4}$ they each will appear in three $\mathrm{SiO}_{x} \mathrm{~N}_{y}$ tetrahedra, and $\mathrm{Si}-\mathrm{O}-\mathrm{Si}$ bridging oxygens will appear in two. The presence of oxygen substitution leads to a significant shielding of the ${ }^{29} \mathrm{Si}$, with typical values of -63 ppm for $\mathrm{SiN}_{3} \mathrm{O},-72 \mathrm{ppm}$ for $\mathrm{SiN}_{2} \mathrm{O}_{2}$ and $-90 \mathrm{ppm}$ for $\mathrm{SiNO}_{3}$. The presence of $\mathrm{OH}$ groups bound to silicon is evidenced by a further shift of the ${ }^{29} \mathrm{Si}$ signal, to below -90 ppm.

Cross polarization (CP) from ${ }^{1} \mathrm{H}$ to ${ }^{29} \mathrm{Si}$ can be used to effectively observe the ${ }^{29} \mathrm{Si}$ nuclei in proximity to ${ }^{1} \mathrm{H}$, taking advantage of the fast relaxation of protons to quickly acquire ${ }^{29} \mathrm{Si}$ spectra with a good signal intensity. CP measurements give information about local structure, but the overall signal intensity depends both on the proton network and on the population of the different types of silicon sites. A sample produced with triflic acid catalyst and fired at $1000{ }^{\circ} \mathrm{C}$ produced a single, symmetric peak at -47 ppm (Fig. 1), similar to the previous reported positions of the $\mathrm{SiN}_{4}$ and near-amide peaks in gel-derived amorphous silicon imidonitrides ${ }^{11,17,18}$ and the ${ }^{29} \mathrm{Si}$ shifts of crystalline $\alpha-\mathrm{Si}_{3} \mathrm{~N}_{4}(-47$ to $-49 \mathrm{ppm}) .{ }^{19}$ The spectra of samples produced with $5 \%$ or $10 \%\left[\mathrm{NH}_{4}\right][\mathrm{OTf}]$
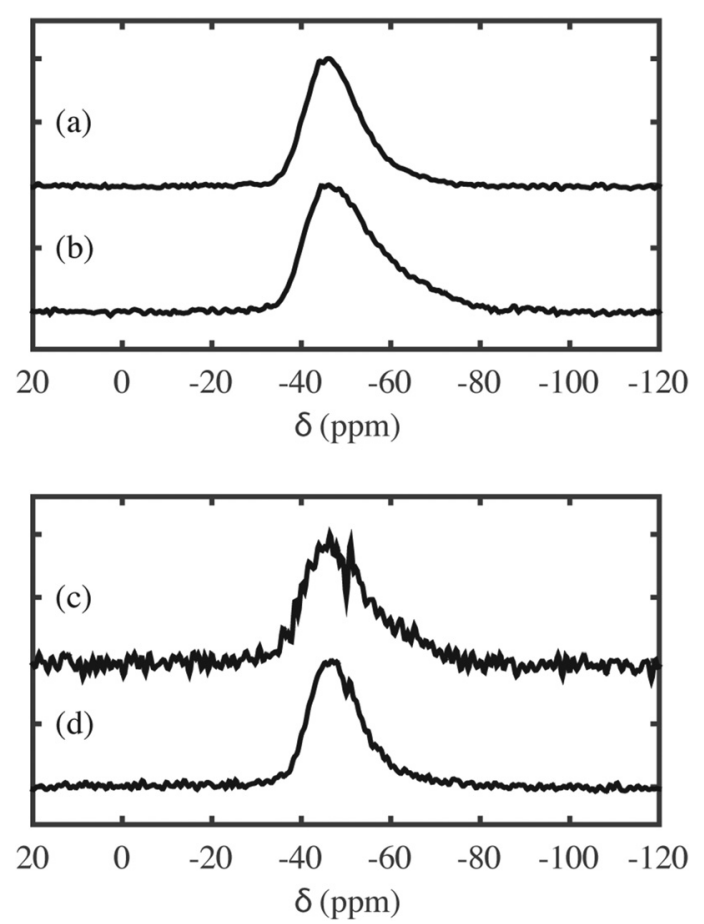

Fig. $1{ }^{29}$ Si CP-MAS NMR spectra of silicon imidonitride samples prepared from triflic acid or ammonium triflate catalysed gels and fired at $1000{ }^{\circ} \mathrm{C}$. Catalyst: (a) 1-2 drops triflic acid; (b) $10 \%\left[\mathrm{NH}_{4}\right][\mathrm{OTf}]$; (c) $5 \%$ $\left[\mathrm{NH}_{4}\right][\mathrm{OTf}] ;$ (d) $0.4 \%\left[\mathrm{NH}_{4}\right][\mathrm{OTf}]$. Note that (a) and (b) were recorded at 14.1 $\mathrm{T}$, whereas $(\mathrm{c})$ and $(\mathrm{d})$ were recorded at $9.4 \mathrm{~T}$. 


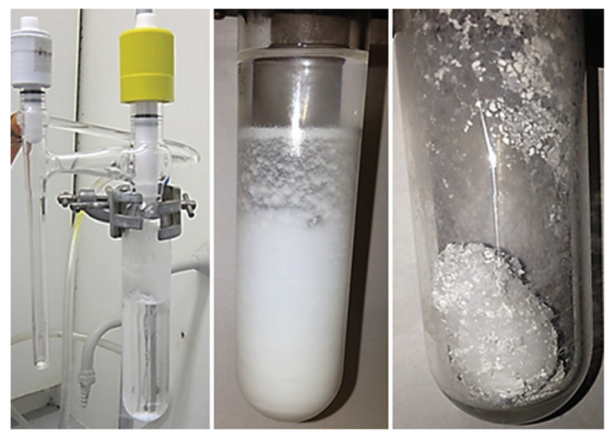

Fig. 2 Images of a typical $\left[\mathrm{NH}_{4}\right][\mathrm{OTf}]$-catalysed silicon imidonitride preparation immediately after warming to ambient temperature (left, showing the side-arm used to measure liquid ammonia), after gelation at $24 \mathrm{~h}$ aging time (centre), and the xerogel after solvent removal (right).

contained a peak in a similar position (Fig. 1(b and c)), but it was observed to be strongly asymmetric suggesting a weak secondary peak at lower chemical shift, consistent with the presence of some $\mathrm{SiON}_{3}$ environments. ${ }^{17,18}$

Using lower amounts of $\left[\mathrm{NH}_{4}\right][\mathrm{OTf}]$ catalyst, gelation occurred over much longer periods, close to $24 \mathrm{~h}$. On allowing the solutions to warm to ambient temperature the clear solutions developed some turbidity over the first hour and then some separation was observed after 3-4 h, with a thin layer of clear solution above a turbid solution. The turbid solution transformed into a gel over the next 10-20 h. In total, gels were aged for $40 \mathrm{~h}$ after ammonia addition before the liquid solvent was decanted and the gel was slowly pumped to dryness (xerogel). Fig. 2 shows the various stages of gel preparation. Firing a xerogel produced using this procedure at $1000{ }^{\circ} \mathrm{C}$ resulted in a sample with no signals in the range -63 to -90 ppm, and hence with oxygen content below that which can be determined by ${ }^{29} \mathrm{Si}$ MAS-NMR (Fig. 1). The lower triflate concentrations also resulted in a further reduction in the number of large spherical particles observed in the fired samples (Fig. S2†).

Thermogravimetric analysis (TGA, Fig. S3†) of xerogels produced with different $\left[\mathrm{NH}_{4}\right][\mathrm{OTf}]$ contents showed that mass loss when heated under argon to $900{ }^{\circ} \mathrm{C}$ was $14 \%$ with $10 \%$ $\left[\mathrm{NH}_{4}\right][\mathrm{OTf}], 20 \%$ with $1 \%\left[\mathrm{NH}_{4}\right][\mathrm{OTf}]$ and $35 \%$ with $0.4 \%$ $\left[\mathrm{NH}_{4}\right][\mathrm{OTf}]$. This suggests that smaller oligomers, which can be lost during heating, are present at higher concentrations in the samples prepared with less catalyst even after $\sim 40 \mathrm{~h}$ aging of the gels. When samples are fired in ammonia further condensation reactions will occur and increase the degree of cross-linking during heating, especially in the initial heating period at moderate temperature $\left(200{ }^{\circ} \mathrm{C}\right)$ that has been used throughout this study.

\section{Structure evolution with temperature in samples prepared with $0.4 \%\left[\mathrm{NH}_{4}\right][\mathrm{OTf}]$}

The specific thermal treatment applied in the preparation of silicon nitride or imidonitride samples will determine the properties of the product, including the concentrations of amide and imide groups necessary for any base catalysis functionality, degree of crystallisation, and microstructure affecting surface area and the type of pore structure present. Hence an exhaustive characterisation of a series of samples, prepared by heating in ammonia under various conditions, was attempted. The xerogels prepared with $0.4 \%\left[\mathrm{NH}_{4}\right][\mathrm{OTf}]$ were chosen as the starting material for the low oxygen contents they provide.

Infrared spectra showed strong $\mathrm{N}-\mathrm{H}$ stretching $\left(\sim 3400 \mathrm{~cm}^{-1}\right)$ and bending $\left(\sim 1600 \mathrm{~cm}^{-1}\right)$ features in samples produced at $200{ }^{\circ} \mathrm{C}$, and these reduced in intensity as the temperature was increased (Fig. 3). Notably the stronger stretching feature was still observable even in samples heated at $1400{ }^{\circ} \mathrm{C}$ for $18 \mathrm{~h}$, presumably because the surface was still terminated with amide groups. Similarly $\mathrm{C}-\mathrm{H}$ stretching $\left(\sim 2900 \mathrm{~cm}^{-1}\right)$ features, that were significant at $200{ }^{\circ} \mathrm{C}$, became weaker with heating as the organic components were pyrolyzed. At low firing temperature the two broad peaks in the Si-N stretching region $\sim 700-1400 \mathrm{~cm}^{-1}$ closely resemble previous silicon imidonitride samples made from $\mathrm{Si}(\mathrm{NHMe})_{4}{ }^{11}$ or $\left[\mathrm{Si}(\mu-\mathrm{NH})\left(\mathrm{NMe}_{2}\right)_{2}\right]_{3} .{ }^{20}$ These merge as the firing temperature is increased to yield a typical $\mathrm{Si}-\mathrm{N}$ stretching frequency of $\sim 960 \mathrm{~cm}^{-1}$ and no $\mathrm{SiO}_{2}$ peak at $\sim 1100 \mathrm{~cm}^{-1} \cdot{ }^{21,22}$ The weak band observed at $\sim 2250 \mathrm{~cm}^{-1}$ in intermediate temperature samples has previously been attributed to $\mathrm{C} \equiv \mathrm{N}$ from pyrolysis of organic amide/imide groups in $\left[\mathrm{Si}(\mu-\mathrm{NH})\left(\mathrm{NMe}_{2}\right)_{2}\right]_{3}$-derived

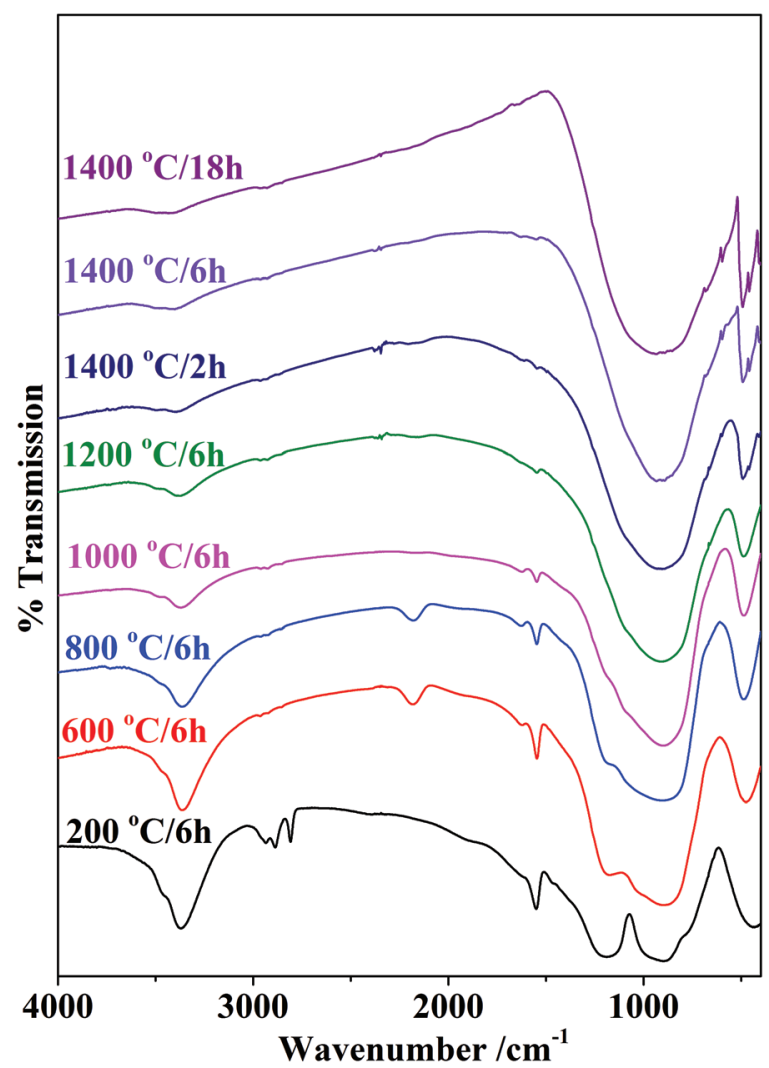

Fig. 3 Infrared spectra of silicon imidonitride/nitride samples produced by heating xerogels made with $0.4 \%\left[\mathrm{NH}_{4}\right][\mathrm{OTf}]$ in ammonia under conditions as shown. 

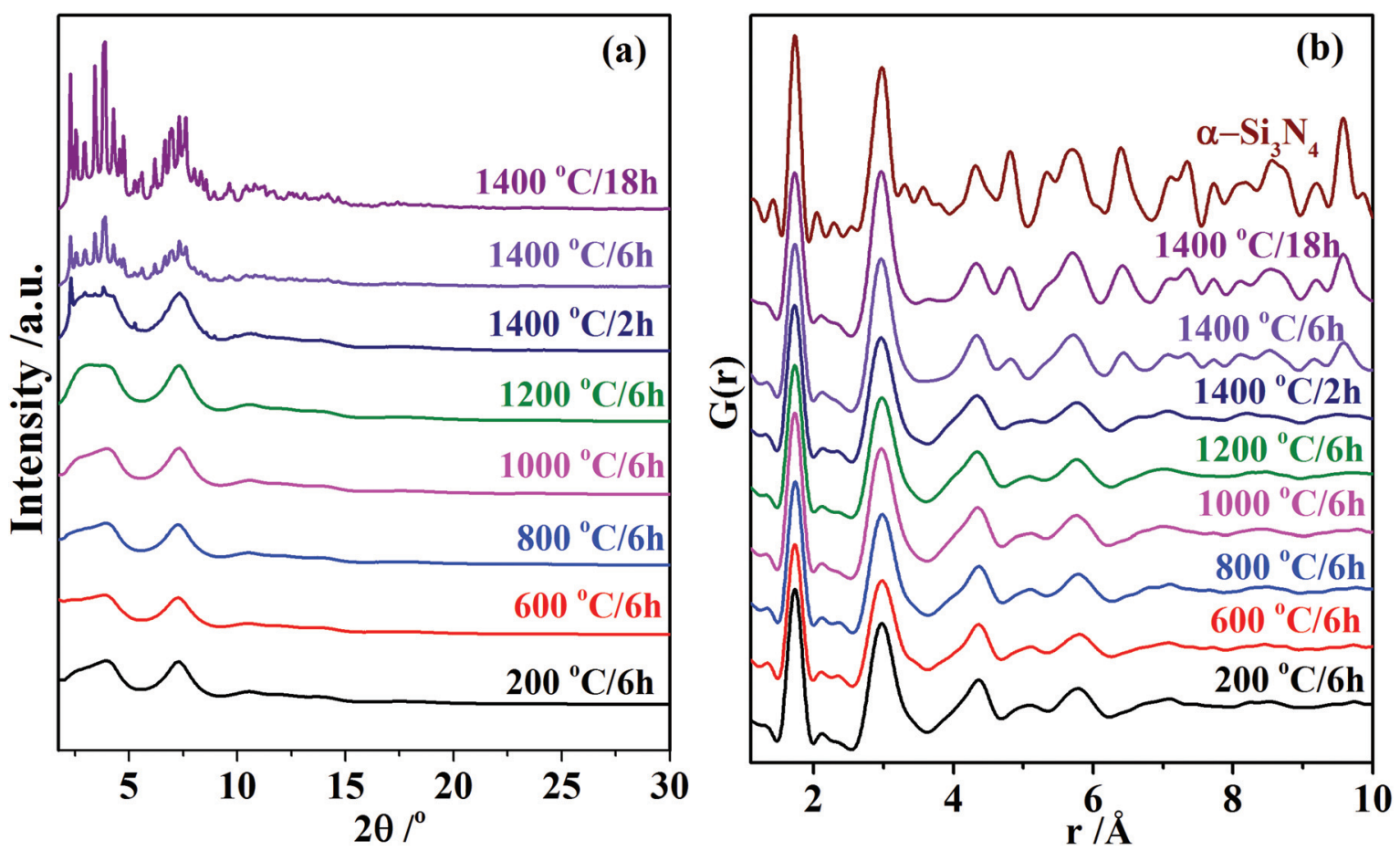

Fig. 4 Total scattering intensity with polyimide capillary subtracted $(a, \lambda=0.1722 \AA)$ and PDFs (b) of silicon imidonitride/nitride samples produced by heating gels made with $0.4 \%\left[\mathrm{NH}_{4}\right][\mathrm{OTf}]$ under conditions as shown, and calculated PDF of $\alpha-\mathrm{Si}_{3} \mathrm{~N}_{4}$ (top right). ${ }^{28}$

xerogels, ${ }^{21}$ or to bridging $\mathrm{Si}-\mathrm{H}-\mathrm{Si}$ units in polysilazane-derived materials. $^{23}$

Powder X-ray diffraction patterns collected on a laboratory system showed samples to be amorphous up to $1200^{\circ} \mathrm{C}$, with slow crystallization at $1400{ }^{\circ} \mathrm{C}$. The correlation length in the amorphous materials is short enough for electron diffraction to also show only broad, amorphous features (Fig. S4†). Synchrotron X-ray total scattering data were collected so that any variations in local, as well as long range, structure could be followed with firing temperature. Fig. 4a shows the diffraction patterns after subtraction of the background due to the polyimide capillaries that held the samples. The patterns all exhibit the same amorphous features from $200-1200{ }^{\circ} \mathrm{C}$, then at $1400{ }^{\circ} \mathrm{C}$ sharp Bragg reflections are seen to develop, superimposed onto the amorphous scattering. The Bragg component becomes more significant with increasing heating time at $1400{ }^{\circ} \mathrm{C}$, but it should be noted that the broad amorphous features are also still present even in the sample heated at this temperature for $18 \mathrm{~h}$. All the sharp reflections match the $\alpha-\mathrm{Si}_{3} \mathrm{~N}_{4}$ polymorph (P31c). This non-centrosymmetric phase (Fig. 5) undergoes an irreversible phase transition into the denser, but $40 \%$ less hard, $\beta-\mathrm{Si}_{3} \mathrm{~N}_{4}$ phase at high temperature. ${ }^{24}$ It is uncommon to obtain phase-pure $\alpha-\mathrm{Si}_{3} \mathrm{~N}_{4}$ and normally it is obtained with a small fraction of the $\beta$-phase. For example, in the preparation of $\mathrm{Si}_{3} \mathrm{~N}_{4}$ from perhydropolysilazane, crystallization was observed at just $1200{ }^{\circ} \mathrm{C}$ but a mixture of $\alpha$ - and $\beta-\mathrm{Si}_{3} \mathrm{~N}_{4}$ was obtained even at this temperature. ${ }^{25}$ Rietveld refinement of the data from our sample fired at $1400{ }^{\circ} \mathrm{C}$ for $18 \mathrm{~h}$ (Fig. S5 and Table S1†) ${ }^{26}$ confirms for- mation of $\alpha-\mathrm{Si}_{3} \mathrm{~N}_{4}$ with no $\beta-\mathrm{Si}_{3} \mathrm{~N}_{4}$. The refined lattice parameters of $a=7.7806(10) \AA$ and $c=5.6423(10) \AA$ are in good agreement with literature reported values of 7.75193(3) and 5.61949(4) А̊. ${ }^{27}$

The structure functions $(S(\mathrm{Q}))$ obtained from the synchrotron diffraction data were of high quality and contained oscillations at least to $Q=25 \AA^{-1}$ (Fig. S6†). Fig. 4b shows the experimental pair distribution functions (PDFs) and a calculated PDF for crystalline $\alpha-\mathrm{Si}_{3} \mathrm{~N}_{4} \cdot{ }^{27}$ The first and second strong peaks at $\sim 1.73$ and $\sim 2.93 \AA$ can be attributed to the nearest neighbour distances $d_{\mathrm{Si}-\mathrm{N}}$, and to a composite of the average nearest $d_{\mathrm{Si}-\mathrm{Si}}$ and $d_{\mathrm{N}-\mathrm{N}}$ contributions, respectively. In the range up to $\sim 5 \AA$ it is striking that there is little difference between samples produced at $200{ }^{\circ} \mathrm{C}$ and $1400{ }^{\circ} \mathrm{C}$, or to the calculated PDF for the fully crystallised material. This is partly because this short range structure consists simply of corner-linked $\mathrm{SiN}_{4}$ tetrahedra, but the effect of some degree of pre-structuring in the precursor system on the final crystallised structure cannot be ruled out, and could explain the presence of a single crystalline phase. We recently described such a phenomenon in the formation of a new $\mathrm{Hf}_{3} \mathrm{~N}_{4}$ polymorph. ${ }^{28}$ An alternative explanation for the formation of the $\alpha-\mathrm{Si}_{3} \mathrm{~N}_{4}$ phase is the incorporation of trace amounts of $\mathrm{Al}$ and $\mathrm{O}$ atoms from the alumina boat, which are known to stabilise this phase. ${ }^{29,30}$ However, these are not present in detectable quantities. Extra features develop at longer distance in the PDFs at $1400{ }^{\circ} \mathrm{C}$ as the samples crystallise, and this is also observed in the intermediate to long range G(r) (Fig. S7 $\dagger$ ). However, the PDF doesn't quite match the theoretical PDF of crystalline $\alpha-\mathrm{Si}_{3} \mathrm{~N}_{4}$ even in 


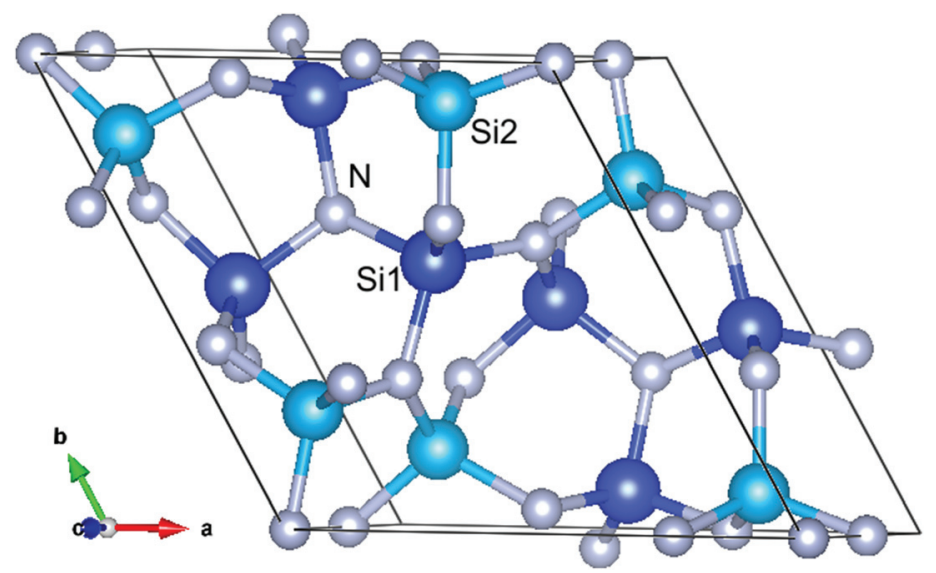

Fig. 5 Plot of the non-centrosymmetric structure of $\alpha-\mathrm{Si}_{3} \mathrm{~N}_{4}$, using the refined atomic coordinates in Table $\mathrm{S}_{\uparrow} \uparrow$ and showing the 6 -membered rings. The Si1 silicon atoms are shown in blue and Si2 in a lighter shade of blue. Nitrogen atoms are shown in grey.

the most crystalline sample, heated for $18 \mathrm{~h}$ at $1400{ }^{\circ} \mathrm{C}$, and the differences increase with correlation length. Amorphous components and the effect of any porosity and hence surface structure, will make significant contributions to the PDFs on this length scale. Fitting the PDF data up to $10 \AA$ to the Rietveld-derived structure (Fig. 6 and Table S2 $\dagger$ ) resulted in lattice parameters of $a=7.760(14)$ and $c=5.614(18) \AA$, a good match to both the Rietveld fit and the literature values for $\alpha-\mathrm{Si}_{3} \mathrm{~N}_{4}$.

Under cross polarization (CP) conditions the ${ }^{29}$ Si MAS-NMR spectra (Fig. 7a) show a single peak in samples produced throughout the range $600-1400{ }^{\circ} \mathrm{C}$. The peak positions of -43

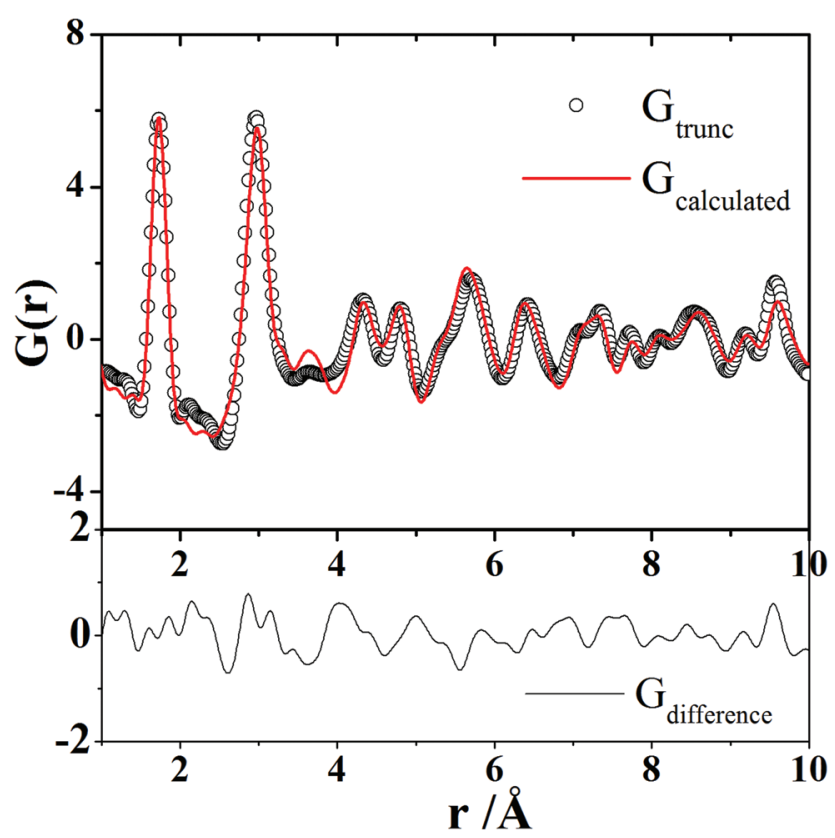

Fig. 6 Real space refinement of the PDF from a silicon imidonitride sample synthesised at $1400{ }^{\circ} \mathrm{C}$ for $18 \mathrm{~h}$. Starting model: $\alpha-\mathrm{Si}_{3} \mathrm{~N}_{4}$ with refined coordinates from the Rietveld refinement of the Bragg pattern described above. to $-47 \mathrm{ppm}$ are in the expected range for the $\mathrm{SiN}_{4}$ and nearamide environments. There is no indication of a secondary peak at lower shift or in the regions associated with the $\mathrm{SiN}_{2} \mathrm{O}_{2}$ and $\mathrm{SiNO}_{3}$ environments (near -69 and $-90 \mathrm{ppm}$ respectively), ${ }^{17}$ suggesting that the concentration of oxygen in the samples is very low. There is no obvious signal even for single oxygen substitution $(-63 \mathrm{ppm})$ within the confidence limits determined by the noise level in the experimental data acquired at $600{ }^{\circ} \mathrm{C}$ in Fig. 7 (a), therefore the $\mathrm{SiN}_{3} \mathrm{O}$ component may be estimated to be less than $1 \%$. Data acquired on a sample produced at $1000{ }^{\circ} \mathrm{C}$ are broader and the presence of single oxygen substitution cannot be entirely ruled out here, but signal deconvolution is compatible with the most shielded signal component arising from a broad signal near $-50 \mathrm{ppm}$ ( $\mathrm{SiN}_{4}$ region), as also observed in previous studies. ${ }^{18}$ The signal becomes weaker as the sample crystallises at $1400{ }^{\circ} \mathrm{C}$. The direct acquisition (DA) ${ }^{29} \mathrm{Si}$ MAS-NMR spectra (Fig. 7b) show the same peak in samples produced at up to $1200{ }^{\circ} \mathrm{C}$, but two sharp peaks grow in as the material crystallises at $1400{ }^{\circ} \mathrm{C}$. The sharp peaks can be attributed to the two $\mathrm{Si}$ environments present in the $\alpha-\mathrm{Si}_{3} \mathrm{~N}_{4}$ crystal structure (Fig. 5 and Table $\mathrm{S} 1 \dagger),{ }^{28}$ and their positions $(-46.3$ and $-48.4 \mathrm{ppm}$ in the $1400{ }^{\circ} \mathrm{C} / 18 \mathrm{~h}$ sample, Table S3†) are similar to those in literature reports for this phase. ${ }^{31}$

The lack of change in the CP-MAS spectra as the sample crystallised, apart from loss of intensity of the signal, shows that it is mainly sensitive to the amorphous phase and hence that the bulk of the protons in these samples are associated with that amorphous component. Even a sample produced at $1400{ }^{\circ} \mathrm{C}$ for $18 \mathrm{~h}$ still showed a background in the direct acquisition MAS spectra due to the amorphous phase, and peak fitting (Table S3 and Fig. S8†) was used to obtain a rough measure of the amorphous content of these samples. The sample prepared by heating at $1400{ }^{\circ} \mathrm{C}$ for $6 \mathrm{~h}$ contained at least $12 \%$ crystalline $\mathrm{Si}_{3} \mathrm{~N}_{4}$, whereas after $18 \mathrm{~h}$ that figure increased to at least $31 \%$. The amount of crystalline phase may be significantly underestimated in both cases due to the longer ${ }^{29} \mathrm{Si}$ relaxation time expected for the crystalline phase. 

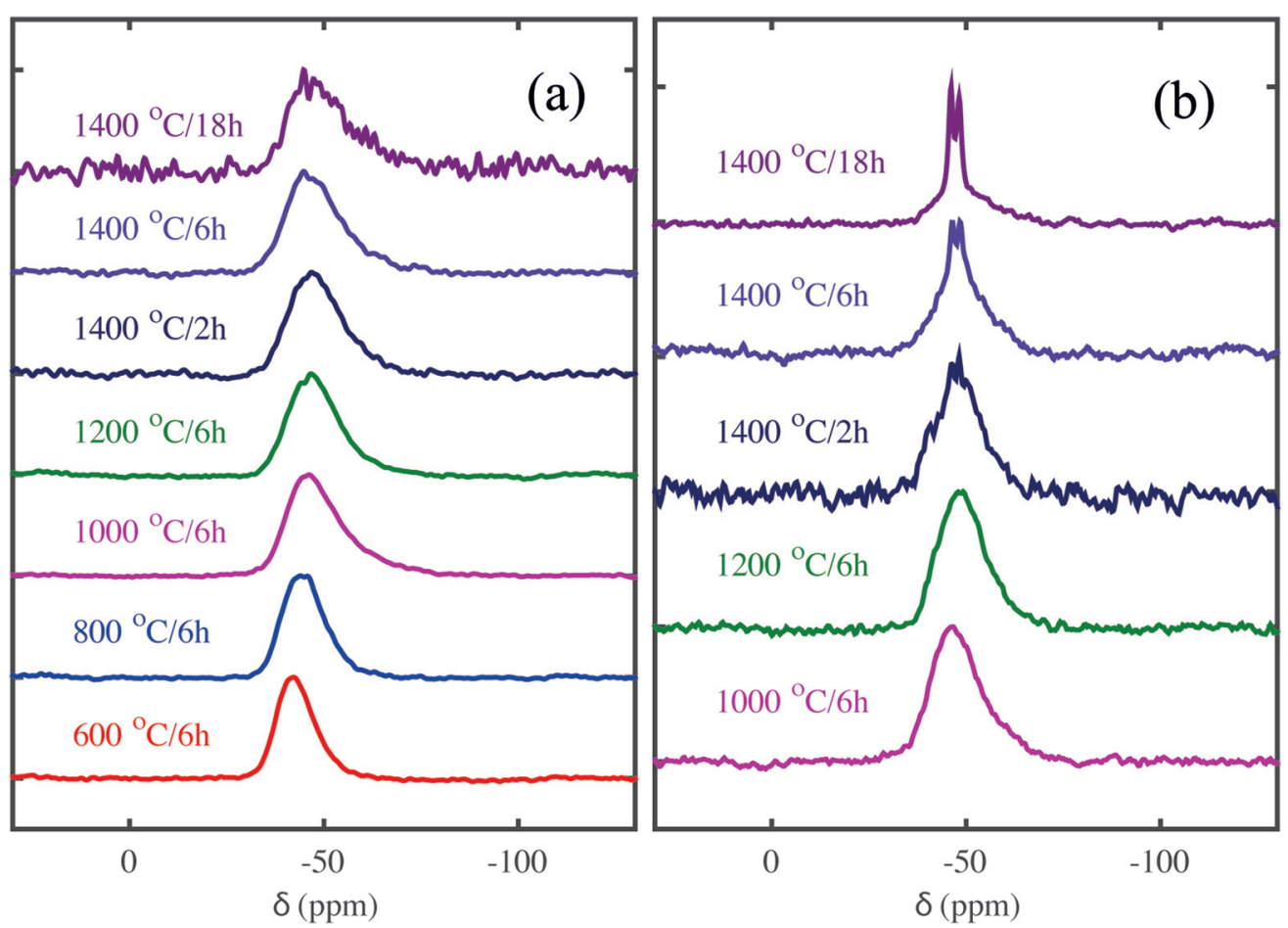

Fig. $7{ }^{29}$ Si NMR spectra of silicon imidonitride/nitride samples produced by heating gels made with $0.4 \%$ [NH $\left.\mathrm{N}_{4}\right][\mathrm{OTf}]$ at the temperatures shown. (a) Shows CP-MAS and (b) direct acquisition spectra.

The ${ }^{1} \mathrm{H}$ MAS-NMR spectra (Fig. 8) show a single asymmetric peak at $\sim 2 \mathrm{ppm}$ in samples prepared at $600-1200{ }^{\circ} \mathrm{C}$. This sharpens and splits into 2 peaks at +5 and $+2 \mathrm{ppm}$ at $1400{ }^{\circ} \mathrm{C}$, which was not expected in the context of the ${ }^{29} \mathrm{Si}$ spectra described above. The second signal could be due to the resolution of more than one type of $\mathrm{N}-\mathrm{H}$ signal (e.g. $-\mathrm{NH}_{2}$ amide and -NH- imide) as the sample becomes more defined, or to a combination of amide groups associated with the crystalline and the amorphous phases. For isolated $\mathrm{Si}-\mathrm{NH}_{x}$ sites we can expect moderately sharp lines as these are not disturbed by ${ }^{1} \mathrm{H}-{ }^{1} \mathrm{H}$ dipolar interactions. The IR spectra indicate that most hydrogen is present as $\mathrm{NH}_{x}$ species and no $\mathrm{Si}-\mathrm{OH}$ signal is observed in the ${ }^{29} \mathrm{Si}$ MAS-NMR spectra, ${ }^{17,18}$ suggesting that this extra signal is not due to hydroxide groups.

SEM showed little variation between samples prepared at temperatures in the range 200 to $1200{ }^{\circ} \mathrm{C}$. During crystallization at $1400{ }^{\circ} \mathrm{C}$ the progressive growth of hexagonal prisms of crystalline $\alpha-\mathrm{Si}_{3} \mathrm{~N}_{4}$ was observed. The relative amounts of relatively formless material to these distinctive crystals (Fig. 9) roughly correlated to the mixtures of amorphous and crystalline material observed via the XRD patterns, the PDF and the NMR. The obvious expectation from examination of these images is that crystallization will severely limit surface area, with clear implications for potential catalytic applications of crystallised materials.

The fired samples generally exhibited type IV nitrogen adsorption-desorption isotherms, indicating mesoporosity. ${ }^{33}$ As anticipated when using $\mathrm{N}_{2}$ as the adsorbate, the desorption branches close at or above a $P / P_{0}$ value of $0.42 .{ }^{34}$ The overall

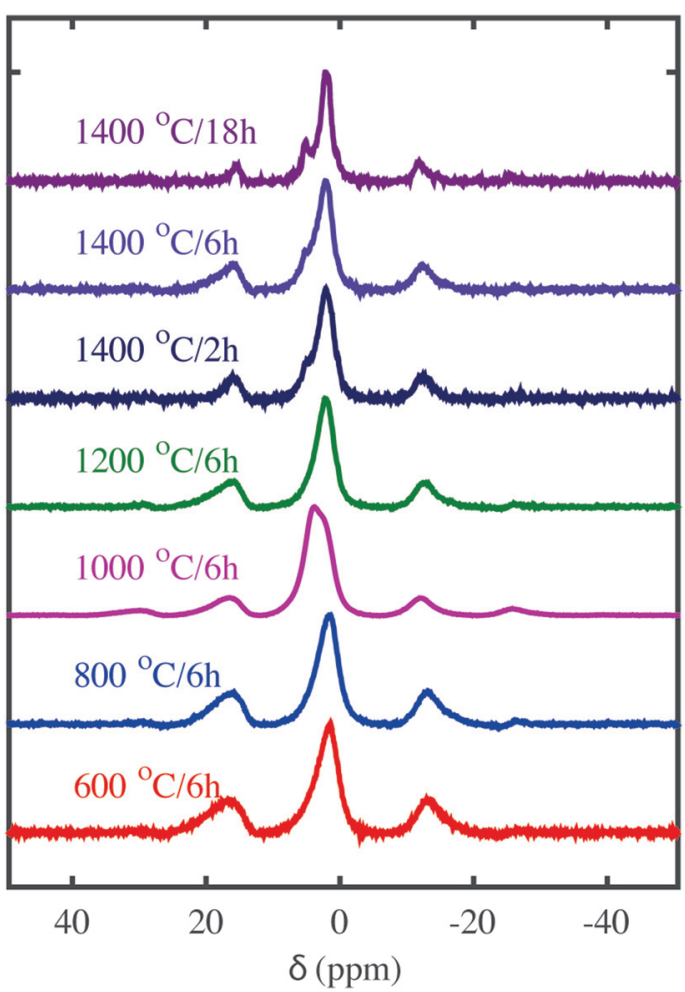

Fig. $8{ }^{1} \mathrm{H}$ MAS-NMR spectra of silicon imidonitride/nitride samples produced by heating gels made with $0.4 \%$ [ $\left.\mathrm{NH}_{4}\right][\mathrm{OTf}]$ at the temperatures shown, using the "aring" pulse sequence ${ }^{32}$ to remove background signals. Note that features below -10 and above 10 ppm are spinning sidebands. 

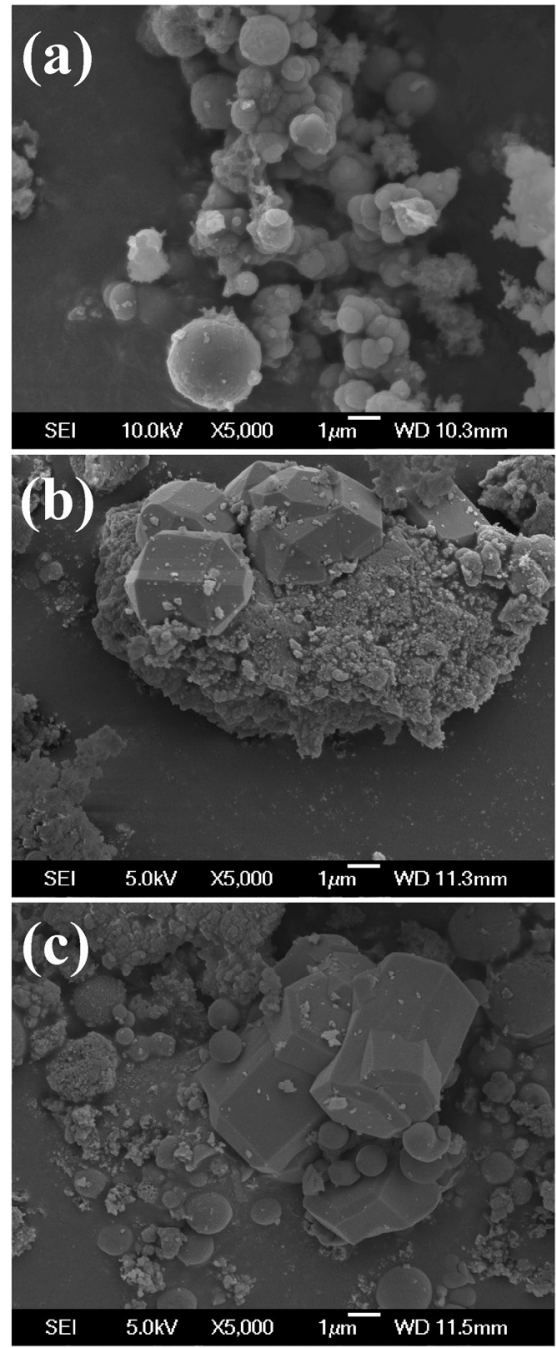

Fig. 9 SEM images of silicon imidonitride/nitride samples produced by heating gels made with $0.4 \%\left[\mathrm{NH}_{4}\right][\mathrm{OTf}]$ at $1400^{\circ} \mathrm{C}$ for $2 \mathrm{~h}(\mathrm{a}), 6 \mathrm{~h}$ (b) or $18 \mathrm{~h}$ (c).

isotherm shapes, however, occur in three distinct types in the temperature ranges $200-600{ }^{\circ} \mathrm{C}, \quad 800-1000{ }^{\circ} \mathrm{C}$ and 1200-1400 ${ }^{\circ} \mathrm{C}$ (Fig. 10). Extraction of the BET surface area ${ }^{35}$ (Fig. 11) resulted in surface areas of $300-400 \mathrm{~m}^{2} \mathrm{~g}^{-1}$ in samples pyrolyzed up to $800{ }^{\circ} \mathrm{C}$, but then lower values at 1200 and $1400{ }^{\circ} \mathrm{C}$, with the latter dropping to $116 \mathrm{~m}^{2} \mathrm{~g}^{-1}$ as the sample starts to crystallise (this value for a sample heated at $1400{ }^{\circ} \mathrm{C}$ for $6 \mathrm{~h}$ ). Loss of surface area above $700-800{ }^{\circ} \mathrm{C}$ has also been observed in other studies of precursor-derived silicon nitride materials. ${ }^{36}$ Higher surface areas up to 1000 $\mathrm{m}^{2} \mathrm{~g}^{-1}$ have previously been achieved in sol-gel samples and those produced by ammonolysis of silicon halides, but NMR data in these papers clearly shows the presence of $\mathrm{SiON}_{3}$ environments at $\sim-63 \mathrm{ppm}^{5,7}$ Surface areas here are more comparable with those obtained in polysilazane-derived foams

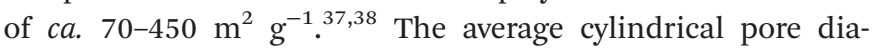
meter $^{36}$ gradually increases from $2 \mathrm{~nm}$ at $200{ }^{\circ} \mathrm{C}$ to $4 \mathrm{~nm}$ at $800{ }^{\circ} \mathrm{C}$, then more steeply to $10 \mathrm{~nm}$ at $1400{ }^{\circ} \mathrm{C}$. These changes

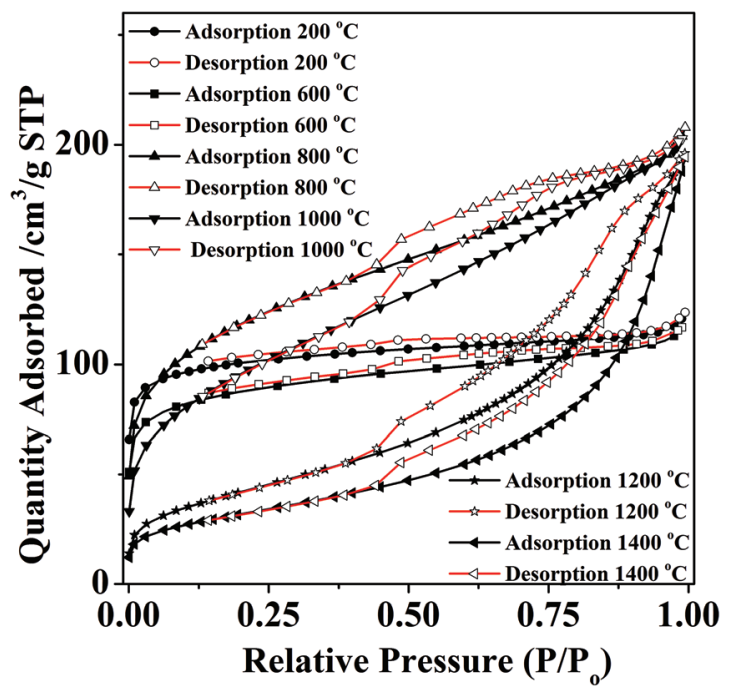

Fig. $10 \mathrm{~N}_{2}$ adsorption-desorption isotherms of silicon imidonitride/ nitride samples produced by heating gels made with $0.4 \%\left[\mathrm{NH}_{4}\right][\mathrm{OTf}]$ at temperatures shown for $6 \mathrm{~h}$.
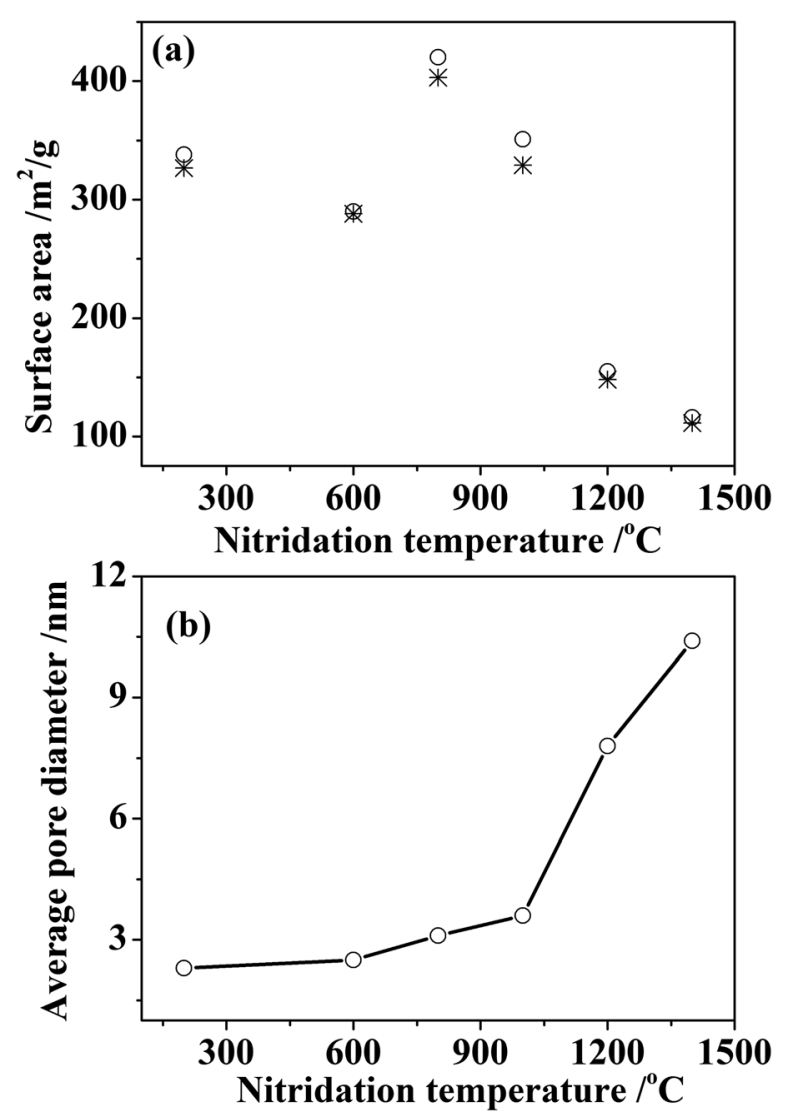

Fig. 11 Heating temperature variation in surface area (a) and average pore size (b) of silicon imidonitride/nitride samples produced by heating gels made with $0.4 \%\left[\mathrm{NH}_{4}\right][\mathrm{OTf}]$ for $6 \mathrm{~h}$. In the surface area plot (a) the open circles are multi point and the stars single point surface area. 


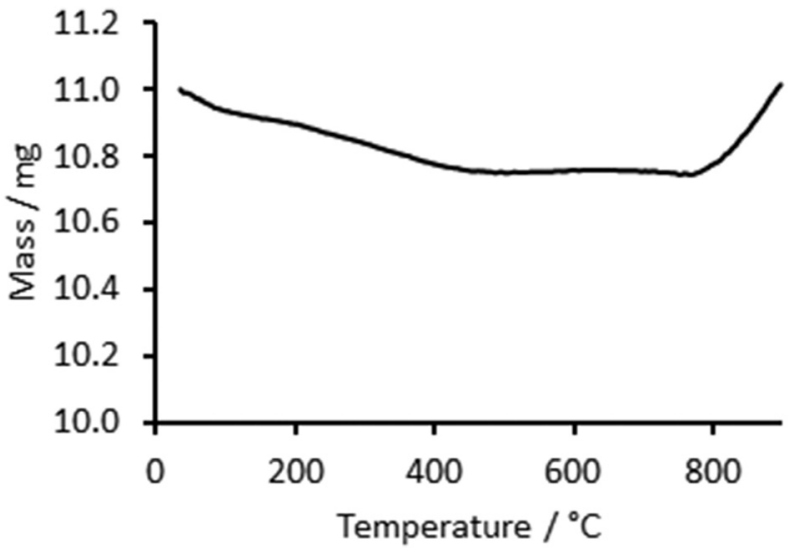

Fig. 12 Oxidative TGA $\left(20 \% \mathrm{O}_{2}\right.$ in $\mathrm{Ar}$ ) of silicon imidonitride/nitride samples produced by heating a gel made with $0.4 \%\left[\mathrm{NH}_{4}\right][\mathrm{OTf}]$ at $1200^{\circ} \mathrm{C}$ for $6 \mathrm{~h}$.

can be related to a balance between loss of porosity due to crystallization, the shrinkage of the pore walls due to further condensation during heating in the ammonia atmosphere resulting in pore opening, and loss of the organic constituents resulting in increased porosity.

In order to evaluate the oxidative stability of the amorphous silicon nitride samples, an important parameter for their catalysis utility, a sample produced at $1200{ }^{\circ} \mathrm{C}$ was heated in an oxidising environment in a TGA (Fig. 12). Oxidation of $\mathrm{Si}_{3} \mathrm{~N}_{4}$ to $\mathrm{SiO}_{2}$ would be observed as a mass increase of $28.6 \%$. The TGA data shows a gradual mass loss of $2.2 \%$ between ambient temperature and $460{ }^{\circ} \mathrm{C}$, presumably due to loss of surface amide/imide groups. The mass profile was then flat until $\sim 770{ }^{\circ} \mathrm{C}$, after which the mass started to increase as the sample oxidised. At $900{ }^{\circ} \mathrm{C}$ the mass had increased by $2.5 \%$ from the plateau value but was still rising steeply. Hence these samples are stable in an oxygen-rich environment to around $770{ }^{\circ} \mathrm{C}$ and could only be used as catalyst supports in oxidising environments below this temperature.

In summary, silicon imidonitride and nitride samples formed from $\mathrm{Si}(\mathrm{NHMe})_{4}$-derived gels catalysed with $0.4 \%$ $\left[\mathrm{NH}_{4}\right][\mathrm{OTf}]$ contain reduced concentrations of amide and imide groups as the firing temperature is increased, but even samples produced at $1400{ }^{\circ} \mathrm{C}$ still have detectable amounts and hence at all temperatures base catalyst functionality is a possibility. The local structure is already very similar at $200{ }^{\circ} \mathrm{C}$ firing temperature to that observed in crystalline $\alpha-\mathrm{Si}_{3} \mathrm{~N}_{4}$, although long range order only develops slowly at $1400^{\circ} \mathrm{C}$. Full crystallization might be achievable at $1600{ }^{\circ} \mathrm{C},{ }^{26}$ although it is likely that this will be accompanied by further loss of surface area, resulting in lower interest for catalytic applications. Samples are low in oxygen and the hydrogen is mainly associated with the amorphous component. They could be used in oxidising environments up to $\sim 770{ }^{\circ} \mathrm{C}$. Samples are mesoporous, with high surface areas in amorphous samples reducing as the samples crystallise. The structural similarity to crystalline $\alpha-\mathrm{Si}_{3} \mathrm{~N}_{4}$ in samples prepared at lower temperatures, where the imidonitrides are amorphous, suggests that it should be possible to make use in catalyst supports of the higher surface areas available before crystallization starts.

\section{Experimental section}

All manipulations were carried out and reagents were stored under nitrogen. THF and pentane were dried by distillation from sodium/benzophenone. Tetrakis(methylamino)silane $\left(\mathrm{Si}(\mathrm{NHMe})_{4}\right)$ was synthesised as described previously ${ }^{11}$ and verified by ${ }^{1} \mathrm{H}$ NMR and elemental analysis. Triflic acid $\left(\mathrm{HOSO}_{2} \mathrm{CF}_{3}, \geq 99 \%\right)$ and ammonium triflate $\left(\left[\mathrm{NH}_{4}\right][\mathrm{OTf}]\right.$ where $[\mathrm{OTf}]^{-}=\left[\mathrm{OSO}_{2} \mathrm{CF}_{3}\right]^{-}, 99 \%$, dried in vacuo) were from Aldrich. Ammonia (anhydrous, BOC) was distilled from $\mathrm{Na} / \mathrm{NH}_{3}$ solutions for gel preparation or by passing through a column of dried 3 Å molecular sieves for high temperature reactions.

Triflic acid-catalysed gels were prepared as described previously. ${ }^{11}$ A typical ammonium triflate-catalysed gel preparation would proceed as follows. Si(NHMe $)_{4}(890 \mathrm{mg}$, $6.00 \mathrm{mmol}$ ) was placed in a pressure tube with a graduated side-arm (Fig. 1) to allow measurement of a quantity of liquid ammonia. $\left[\mathrm{NH}_{4}\right][\mathrm{OTf}]$ was added from an appropriate stock solution (e.g. $2 \mathrm{~cm}^{3}$ of a $0.012 \mathrm{~mol} \mathrm{dm}^{-3}$ solution = $0.024 \mathrm{mmol}$ to achieve $0.4 \%$ catalyst relative to the $\mathrm{Si}(\mathrm{NHMe})_{4}$ ) and the solvent was then made up to a total volume of $20 \mathrm{~cm}^{3}$ $\left(18 \mathrm{~cm}^{3}\right.$ added in the case where $2 \mathrm{~cm}^{3}\left[\mathrm{NH}_{4}\right][\mathrm{OTf}]$ stock solution was used). The solution was stirred at room temperature for $1 \mathrm{~h}$ and then $1 \mathrm{~cm}^{3}$ ( $\left.\sim 40 \mathrm{mmol}\right)$ of dry liquid ammonia was condensed into the solution at $-78{ }^{\circ} \mathrm{C}$ without stirring. The solution was allowed to warm to ambient temperature and the clear solution was allowed to age over a period of $\sim 40 \mathrm{~h}$, during which time a rigid monolithic gel formed. After aging $\sim 10 \mathrm{~cm}^{3}$ colourless liquid was decanted under $\mathrm{N}_{2}$ and the remaining solvent was removed slowly in vacuo. The white xerogel powder was stored in a glove box (yield $\sim 430 \mathrm{mg}$ ).

Pyrolysis experiments used quartz (up to $1000{ }^{\circ} \mathrm{C}$ ) or alumina (1000-1400 ${ }^{\circ} \mathrm{C}$ ) furnace tubes sealed with a series of taps to allow glove box loading and flushing of all hoses before opening the sample to the gas stream. Around $500 \mathrm{mg}$ dried gel was placed in a high alumina boat and inside the furnace tube. The furnace was heated to $200{ }^{\circ} \mathrm{C}$ at $2^{\circ} \mathrm{C} \mathrm{min}-1$ and held at $6 \mathrm{~h}$ to maximise crosslinking and methylamide removal, then heated at $2{ }^{\circ} \mathrm{C} \mathrm{min}^{-1}$ to between 600 and $1400{ }^{\circ} \mathrm{C}$ for between 2 and $18 \mathrm{~h}$. Samples were cooled at $5{ }^{\circ} \mathrm{C} \mathrm{min}^{-1}$. Typical ceramic yields from gels prepared with $0.4 \%$ $\left[\mathrm{NH}_{4}\right][\mathrm{OTf}]: 200{ }^{\circ} \mathrm{C} 6$ h 97\%; $600{ }^{\circ} \mathrm{C} 6$ h 69\%; $800{ }^{\circ} \mathrm{C} 6$ h 65\%; $1000{ }^{\circ} \mathrm{C} 6 \mathrm{~h} 64 \% ; 1200{ }^{\circ} \mathrm{C} 6 \mathrm{~h} 56 \% ; 1400{ }^{\circ} \mathrm{C} 2 \mathrm{~h} 62 \% ; 1400{ }^{\circ} \mathrm{C}$ 6 h $62.5 \% ; 1400{ }^{\circ} \mathrm{C} 18$ h $59 \%$.

Surface area and pore size analysis by nitrogen porosimetry used a Micromeritics 3-Flex with 100-120 mg samples degassed under vacuum at $150{ }^{\circ} \mathrm{C}$ overnight. Surface area analysis used the BET method using single point at $P / P_{\mathrm{o}}=0.2665$ or multiple point within appropriate $P / P_{\mathrm{o}}$ region. Adsorption average pore diameter $\left(4 \mathrm{~V} \mathrm{~A}^{-1}\right)$ is reported. ${ }^{36}$ Thermogravimetric analysis (TGA) of gels used a Mettler-Toledo TGA 
851e inside a glove box, and samples were heated under $\mathrm{Ar}$ $\left(65 \mathrm{~cm}^{3} \mathrm{~min}^{-1}\right.$ ) at $10^{\circ} \mathrm{C} \mathrm{min}^{-1}$ to $900{ }^{\circ} \mathrm{C}$. Oxidative TGA used a Netzsch TG209-F1 with the sample heated under $20 \% \mathrm{O}_{2}$ in $\mathrm{Ar}$ $\left(50 \mathrm{~cm}^{3} \mathrm{~min}^{-1}\right)$ at $20^{\circ} \mathrm{C} \mathrm{min}^{-1}$ to $900{ }^{\circ} \mathrm{C}$. Routine X-ray diffraction experiments used a Bruker D2 (Cu- $\mathrm{K}_{\alpha}$ X-rays). Scanning electron micrographs were recorded on a Jeol JSM-6500F with 5 or $10 \mathrm{kV}$ accelerating voltage Transmission electron micrographs were collected on samples dispersed into toluene and dropped onto carbon-coated Cu grids, using a FEI Tecnai T12 or Jeol JEM-300 microscope. Samples for IR spectroscopy were ground in the glove box with $\mathrm{KBr}$ (spectroscopic grade, dried under vacuum at $80{ }^{\circ} \mathrm{C}$ ), pressed into disks and collected in transmission with a Perkin Elmer Spectrum 100 spectrometer.

Synchrotron total scattering experiments used beam line I15 at the Diamond Light Source, with $72.00 \mathrm{keV}(\lambda=0.1722 \AA)$ $\mathrm{X}$-rays and a Perkin Elmer flat panel detector. Samples were packed into polyimide capillaries (0.04 inch diameter, Cole Palmer) sealed with epoxy resin. Sample to detector distance and tilt of the detector were calibrated within Fit2D using $\mathrm{CeO}_{2}$ as standard, ${ }^{39}$ then the two dimensional detector images were integrated within Fit2D to obtain 1D diffraction patterns. $^{40,41}$ Integrated powder diffraction data were used for generation of the pair distribution functions (PDFs) using PDFgetX2. ${ }^{42}$ Intensity was corrected by subtracting data from an empty capillary, and was truncated at a minimum momentum transfer value of $1.5 \AA^{-1}$. In order to optimise oscillation of the structure function $S(Q)$ within $10-25 \AA^{-1}$, corrections due to multiple and Compton scattering, oblique incidence, and energy dependent terms were employed. Thus, the reduced structure function $F(Q)=[Q(S(Q)-1)]$ was obtained by using $Q_{\max }=25 \AA^{-1}$ and interpolating the lower limit of $Q$ to zero. PDFs were obtained by Fourier transformation of $F(Q)$. Rietveld refinements of Bragg data used $\mathrm{GSAS}^{43}$ and a literature model. ${ }^{27}$ PDF calculation and refinement used PDFGUI, ${ }^{44}$ with fixed atom positions from the Bragg refinement and thermal parameters constrained to the same values for each element.

${ }^{1} \mathrm{H}$ and ${ }^{29} \mathrm{Si}$ MAS-NMR spectra were acquired at two magnetic fields. The data at 9.4 $\mathrm{T}$ were obtained using a wide bore Bruker AVANCE II magnet on a Chemagnetics Infinity console and a $4 \mathrm{~mm}$ double resonance APEX probe, tuned to ${ }^{1} \mathrm{H}$ and ${ }^{29} \mathrm{Si}$ with resonance frequencies of $400.8 \mathrm{MHz}$ and $79.6 \mathrm{MHz}$ respectively. The data at $14.1 \mathrm{~T}$ were obtained on a wide bore Bruker Avance II spectrometer using a Bruker double resonance $4 \mathrm{~mm}$ probe, tuned to ${ }^{1} \mathrm{H}$ and ${ }^{29} \mathrm{Si}$ with resonance frequencies of $600.4 \mathrm{MHz}$ and $119.3 \mathrm{MHz}$ respectively. The ${ }^{29} \mathrm{Si}$ scale was referenced to silicone rubber as a secondary reference at $-22.3 \mathrm{ppm}$ with respect to TMS. ${ }^{45}{ }^{1} \mathrm{H}$ spectra were referenced to adamantane at $1.8 \mathrm{ppm}$. For all samples, approximately $40 \mathrm{mg}$ to $80 \mathrm{mg}$ of material was transferred to a normal wall zirconium oxide rotor and spun at $8 \mathrm{kHz}$. Nitrogen boil-off gas was used for bearing and drive gases for magicangle spinning (MAS) in order to prevent oxidation of the samples prepared from temperatures of $1200{ }^{\circ} \mathrm{C}$ and below. Experiments on the samples undergoing heat treatment at $1400{ }^{\circ} \mathrm{C}$ were performed in dry compressed air, as these samples are expected to be more stable. ${ }^{1} \mathrm{H}$ data was acquired using a composite pulse in order to remove signals originating from the background. ${ }^{29} \mathrm{Si}$ spectra were obtained using both single-pulse direct acquisition (with 128 scans, 10 minutes repetition delay and $\pi / 4$ flip angle for the pulse), and ramped cross polarization with a contact time ranging between 4-8 ms and an amplitude ramp of $5 \%,{ }^{1} \mathrm{H}$ SPINAL64 decoupling with a nutation frequency of $80 \mathrm{kHz}$ removed heteronuclear interactions between ${ }^{1} \mathrm{H}$ and ${ }^{29} \mathrm{Si}$. All spectra were processed using matNMR. ${ }^{46}$

\section{Conclusions}

Ammonium triflate provides a well-controlled catalyst for the ammonia-driven gelation of $\mathrm{Si}(\mathrm{NHMe})_{4}$. The presence of triflate also introduced oxygen to silicon imidonitrides produced from these gels, but very low triflate concentrations are effective in catalysing gelation, meaning that oxygen content is below detectable levels. Amorphous silicon imidonitride is obtained when $\mathrm{Si}(\mathrm{NHMe})_{4}$-derived gels are fired in ammonia at temperatures up to $1200^{\circ} \mathrm{C}$. These samples contain organic components in samples fired at lower temperatures and amide/imide groups persist even up to $1400{ }^{\circ} \mathrm{C}$. High surface areas are achieved, of up to $\sim 400 \mathrm{~m}^{2} \mathrm{~g}^{-1}$, indicating strong potential for catalysis either as active materials or as supports. Slow crystallization to the $\alpha-\mathrm{Si}_{3} \mathrm{~N}_{4}$ phase occurs at $1400{ }^{\circ} \mathrm{C}$, unusually with no $\beta-\mathrm{Si}_{3} \mathrm{~N}_{4}$ observed in the products. Structural studies show strong similarities in short range order between samples produced at 200 and $1400{ }^{\circ} \mathrm{C}$, suggesting that the structural behaviour may be strongly influenced by the initial gelation chemistry.

\section{Acknowledgements}

The authors thank EPSRC for funding this work under EP/J019208/1 and EP/J018384/1, the Royal Society for a University Research Fellowship to MC, Diamond Light Source for beam time under EE9124, Dr Annette Kleppe for assistance with total scattering data collection, Dr Shuncai Wang for collecting some of the TEM data, Mr Samuel Fitch for collecting the oxidative TGA, and Dr Darren Bradshaw and Dr Samir El Hankari for access to and assistance with the nitrogen porosimetry equipment.

\section{Notes and references}

1 I. Kurzina, F. J. Cadete Santos Aires, G. Bergeret and J. C. Bertolini, Chem. Eng. J., 2005, 107, 45-53.

2 F. J. Cadete Santos Aires and J. C. Bertolini, Top. Catal., 2009, 52, 1492-1505.

3 A. L. Hector, Chem. Soc. Rev., 2007, 36, 1745-1753.

4 B. Mazumder and A. L. Hector, Top. Catal., 2009, 52, 14721481. 
5 S. Kaskel, K. Schlichte and B. Zibrowius, Phys. Chem. Chem. Phys., 2002, 4, 1675-1681.

6 R. Rovai, C. W. Lehmann and J. S. Bradley, Angew. Chem., Int. Ed., 1999, 38, 2036-2038.

7 D. Farrusseng, K. Schlichte, B. Spliethoff, A. Wingen, S. Kaskel, J. S. Bradley and F. Schüth, Angew. Chem., Int. Ed., 2001, 40, 4204-4207.

8 F. Cheng, S. J. Archibald, S. Clark, B. Toury, S. M. Kelly and J. S. Bradley, Chem. Mater., 2003, 15, 4651-4657.

9 S. Hassan, A. L. Hector and A. Kalaji, J. Mater. Chem., 2011, 21, 6370-6374.

10 F. Cheng, S. M. Kelly, S. Clark, J. S. Bradley, M. Baumbach and A. Schütze, J. Membr. Sci., 2006, 280, 530-535.

11 S. Hassan, A. L. Hector, J. R. Hyde, A. Kalaji and D. C. Smith, Chem. Commun., 2008, 5304-5306.

12 V. Rocher, S. M. Kelly and A. L. Hector, Microporous Mesoporous Mater., 2012, 156, 196-201.

13 J. Loffelholz, J. Engering and M. Jansen, Z. Anorg. Allg. Chem., 2000, 626, 963-968.

14 F. Cheng, S. M. Kelly, S. Clark, J. S. Bradley and F. Lefebvre, J. Organomet. Chem., 2007, 692, 3816-3822.

15 S. I. U. Shah and A. L. Hector, Top. Catal., 2012, 55, 950954.

16 R. Van Weeren, E. A. Leone, S. Curran, L. C. Klein and S. C. Danforth, J. Am. Ceram. Soc., 1994, 77, 2699-2702.

17 E. A. Leone, S. Curran, M. E. Kotun, G. Carrasquillo, R. van Weeren and S. C. Danforth, J. Am. Ceram. Soc., 1996, 79, 513-517.

18 F. Cheng, S. M. Kelly, F. Lefebvre, A. F. Lee, K. Wilson, S. Clark and J. S. Bradley, J. Mater. Chem., 2005, 15, 30393044 .

19 K. R. Carduner, C. S. Blackwell, W. B. Hammond, F. Reidlinger and G. R. Hatfield, J. Am. Chem. Soc., 1990, 112, 4676-4679.

20 F. Cheng, S. Clark, S. M. Kelly and J. S. Bradley, J. Am. Ceram. Soc., 2004, 87, 1413-1417.

21 M. Halamka, S. Kavecky, B. Dočekal, J. Madejová and P. Šajgalík, Ceramics, 2003, 47, 88-93.

22 M. L. Naiman, C. T. Kirk, R. J. Aucoin, F. L. Terry, P. W. Wyatt and S. D. Senturia, J. Electrochem. Soc., 1984, 131, 637-640.

23 J. Schumacher, F. Berger, M. Weinmann, J. Bill, F. Aldinger and F. Müller, Appl. Organomet. Chem., 2001, 15, 809-819.

24 I.-W. Chen and A. Rosenflanz, Nature, 1997, 389, 701-704.

25 Y. Iwamoto, W. Völger, E. Kroke, R. Riedel, T. Saitou and K. Matsunaga, J. Am. Ceram. Soc., 2001, 84, 2170-2178.
26 H. Torya, J. Appl. Crystallogr., 2000, 33, 95-102.

27 R. Marchand, Y. Laurent and J. Lang, Acta Crystallogr., Sect. B: Struct. Crystallogr. Cryst. Chem., 1969, 25, 2157-2160.

28 A. Salamat, A. L. Hector, B. M. Gray, S. A. J. Kimber, P. Bouvier and P. F. McMillan, J. Am. Chem. Soc., 2013, 135, 9503-9511.

29 C.-M. Wang, X. Pan, M. Rohle, F. L. Riley and M. Mitomo, J. Mater. Sci., 1996, 31, 5281-5298.

30 J. C. Idrobo, M. P. Oxley, W. Walkosz, R. F. Klie, S. Öğüt, B. Mikijelj, S. J. Pennycook and S. T. Pantelides, Appl. Phys. Lett., 2009, 95, 164101-164103.

31 K. R. Carduner, R. O. Carter III, M. E. Milberg and G. M. Crosbie, Anal. Chem., 1987, 59, 2794-2797.

32 S. L. Patt, J. Magn. Reson., 1982, 49, 161-163.

33 J. Rouquerol, D. Avnir, C. W. Fairbridge, D. H. Everett, J. M. Haynes, N. Pernicone, J. D. Ramsay, K. S. W. Sing and K. K. Unger, Pure Appl. Chem., 1994, 66, 1739-1758.

34 C. Weidenthaler, Nanoscale, 2011, 3, 792-810.

35 K. S. W. Sing, D. H. Everett, R. A. W. Haul, L. Moscou, R. A. Pierotti, J. Rouquérol and T. Siemieniewska, Pure Appl. Chem., 1985, 57, 603-619.

36 C. Schitco, M. S. Bazarjani, R. Riedel and A. Gurlo, J. Mater. Chem. A, 2015, 3, 805-818.

37 H. Wang, S.-Y. Zheng, X.-D. Li and D.-P. Kim, Microporous Mesoporous Mater., 2005, 80, 357-362.

38 J. Yan, L.-Y. Hong, A. Wang and D.-P. Kim, Solid State Phenom., 2007, 124-126, 727-730.

39 A. P. Hammersley, Report ESRF98HA01T, "FIT2D: V9.129 Reference Manual V3.1” European Synchrotron Radiation Facility,Grenoble, France, 1998.

40 A. P. Hammersley, ESRF Internal Report ESRF97HA02T, "FIT2D: An Introduction and Overview", European Synchrotron Radiation Facility,Grenoble, France, 1997.

41 A. P. Hammersley, S. O. Svensson, M. Hanfland, A. N. Fitch and D. Häusermann, High Pressure Res., 1996, 14, 235-248.

42 X. Qiu, J. W. Thompson and S. J. L. Billinge, J. Appl. Crystallogr., 2004, 37, 678-678.

43 A. C. Larson and R. B. Von Dreele, Generalized Structure Analysis, Los Alamos National Laboratory Report LAUR 86-748, 2000.

44 C. L. Farrow, P. Juhas, J. W. Liu, D. Bryndin, E. S. Bozin, J. Bloch, T. Proffen and S. J. L. Billinge, J. Phys.: Condens. Matter, 2007, 19, 335219.

45 C. R. Morcombe and K. W. Zilm, J. Magn. Reson., 2003, 162, 479-486.

46 J. D. Van Beek, J. Magn. Reson., 2007, 187, 19-26. 